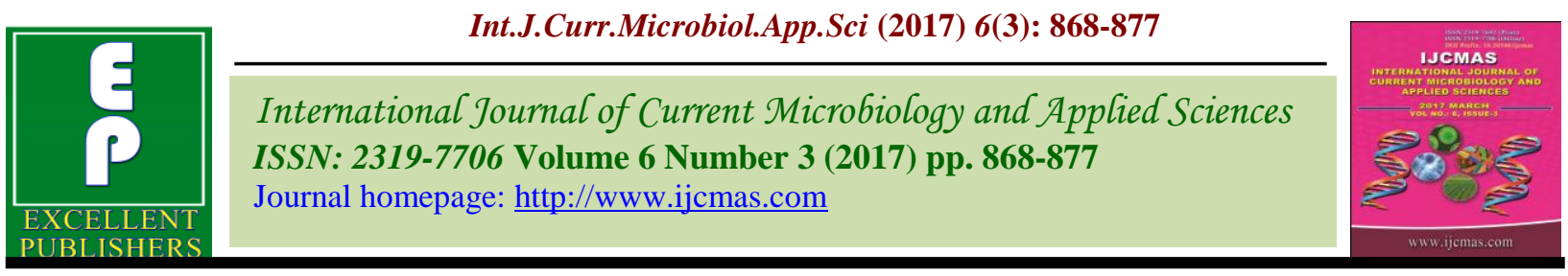

Original Research Article

https://doi.org/10.20546/ijcmas.2017.603.102

\title{
AmpC and Extended Spectrum Beta Lactamase Producing Isolates of E. coli, Klebsiella spp. and $P$. mirabilis in a Tertiary Care Center and their Sensitivity to Other Antibiotics
}

\author{
V.L. Dudhat*, C.N. Chaudhari, Mahadevan Kumar, N. Grover and N.K. Das
}

Department of Microbiology, Microbiology and HIC, Sahyadri Speciality Labs, Pune, India

*Corresponding author:

\begin{tabular}{|c|c|}
\hline & A B S T R A C T \\
\hline & cause protean infections and are the common Gram negative isolates \\
\hline Keywords & $\begin{array}{l}\text { in a microbiology laboratory. Spectrum of multi-drug resistance includes AmpC, Extended } \\
\text { spectrum beta lactamase and carbapenemase production with others. This was a cross }\end{array}$ \\
\hline $\mathrm{AmpC}$ and & sectional study to determine susceptibility pattern of AmpC and extended spectrum beta \\
\hline $\begin{array}{l}\text { Extended Spectrum } \\
\text { Beta Lactamase }\end{array}$ & $\begin{array}{l}\text { lactamase producing isolates against different antimicrobials. There was significant } \\
\text { difference between the pure AmpC producing, pure ESBL producing. AmpC ESBL co- }\end{array}$ \\
\hline & producing and AmpC ESBL non-producing isolates of E. coli, Klebsiella spp. and $P$. \\
\hline Article Info & $\begin{array}{l}\text { mirabilis regarding the resistance pattern against amoxycillin-clavulanate, piperacillin- } \\
\text { tazobactam and co-trimoxazole for which the higher number of pure AmpC producers or }\end{array}$ \\
\hline $\begin{array}{l}\text { Accepted: } \\
15 \text { February } 2017 \\
\text { Available Online: } \\
10 \text { March } 2017\end{array}$ & $\begin{array}{l}\text { AmpC ESBL co-producers were found to be resistant as compared to pure ESBL } \\
\text { producers. In adition, there was significant difference in the resistance pattern against } \\
\text { imipenem and chloramphenicol among pure AmpC producing, pure ESBL producing, } \\
\text { AmpC ESBL co-producing and AmpC ESBL non-producing isolates of E. coli, }\end{array}$ \\
\hline & $\begin{array}{l}\text { sulfonamide in case of Klebsiella spp and imipenem in case of } P \text {. mirabilis isolates. The } \\
\text { difference can be justified by the fact that the AmpC producers are not inhibited by the } \\
\text { beta lactamase inhibitors like clavulanic acid. }\end{array}$ \\
\hline
\end{tabular}

\section{Introduction}

Enterobacteriaceae cause protean infections in both community and the hospital setting (Mackowiak et al., 1978; Johanson et al., 1969). They comprise the most common Gram-negative isolates in microbiology laboratories, including the vast majority of urinary isolates and a large proportion of isolates from the blood, the peritoneal cavity, and the respiratory tract and isolated from other sites too (Donnenberg, 2012). The spectrum of multidrug-resistant Gramnegative organisms (MDRGN) including AmpC, extended spectrum $\beta$-lactamases
(ESBLs) and carbapenemase producer continues to evolve. Beginning in the 1980s and with increasing speed over the past decade, the Enterobacteriaceae have become more resistant and, hence, a major concern (Savard and Perl, 2012).

Beta-lactam antibiotics are commonest antibiotics used in treatment of infections due to Gram negative organisms. The prevalence of multidrug resistant Gram negative bacteria (including $\beta$-lactam antibiotics) is on a rise in the recent past and the AmpC $\beta$-lactamases 
and/or ESBL production has been a matter of concern (Peter-Getzlaff et al., 2011). AmpC producing isolates have been obtained from intensive care units, long term care facilities, rehabilitation centers and OPDs (PeterGetzlaff et al., 2011). This study was undertaken to study the prevalence of AmpC $\beta$-lactamase and ESBL producers at a tertiary care center and to study the susceptibility pattern of these isolates against different antimicrobials.

\section{Materials and Methods}

The study was carried out at a tertiary care center from Nov 2012 to Oct 2014. Two hundred clinical isolates which included $E$. coli, Klebsiella spp and P. mirabilis were collected and tested. The organisms were identified on the basis of colony morphology and biochemical reactions as per conventional isolation and identification procedure (Chirchton, 1996). All isolates were subjected for antibiotic susceptibility testing using Kirby Bauer Disk diffusion method as per CLSI 2012 guidelines (CLSI, 2012).

\section{Screening tests for $\boldsymbol{\beta}$ lactamase production}

Isolates were screened for AmpC $\beta$-lactamase production using $30 \mu \mathrm{g}$ cefoxitin disc $(\mathrm{CX})$ by disc diffusion method as per CLSI guidelines (CLSI 2012). Isolates showing zone of inhibition $\leq 18 \mathrm{~mm}$ were considered as nonsusceptible to cefoxitin (CX) i.e. potential $\beta$ lactamase producer. These isolates were subjected to confirmatory tests for AmpC $\beta$ lactamase production.

Screening for ESBL production was done using $30 \mu \mathrm{g}$ ceftazidime disc (CAZ) by disc diffusion method as per CLSI guidelines (CLSI 2012). Isolates showing zone of inhibition $\leq 22 \mathrm{~mm}$ were considered as nonsusceptible to ceftazidime (CAZ) i.e. potential ESBL producer. These isolates were subjected to confirmatory test for ESBL production.

\section{Confirmatory Tests}

Disc Potentiation Test (using cefoxitin and cefoxitin/boronic acid) (Pitout et al., 2010)

The isolate to be tested was inoculated on MHA using standard method (CLSI, 2012). $\mathrm{CX}(30 \mu \mathrm{g})$ and $\mathrm{CX}+\mathrm{BA}(30 \mu \mathrm{g}+400 \mu \mathrm{g})$ are placed on inoculated MHA and incubated overnight at $37^{\circ} \mathrm{C}$. The difference in diameters of zone of inhibition noted. An organism showing difference in the diameters of zone of inhibition $\geq 5 \mathrm{~mm}$ was considered AmpC $\beta$ lactamase producer (Image 1). Boronic acid is reversible inhibitor of AmpC $\beta$ lactamase enzyme. It binds tightly to AmpC and brings about a structure based mechanism of inhibition.

\section{Double Disc Diffusion Test (DDDT) (Grover et al., 2013)}

A disc of ceftazidime (CAZ) $(30 \mu \mathrm{g})$ alone and a disc of ceftazidime in combination with clavulanic acid (CAC) $(30 / 10 \mu \mathrm{g})$ were used for each isolates. Both the discs were placed on a lawn culture of the test isolate on MHA plate and incubated overnight at $37^{\circ} \mathrm{C}$. A $\geq 5$ $\mathrm{mm}$ increase in zone diameter for either antimicrobial agent tested in combination with clavulanic acid versus its zone when tested alone was designated as ESBL positive (Image 2). Clavulanic acid inhibits the extended spectrum $\beta$ - lactamase enzyme and there is enhanced zone of inhibition around disc containing clavulanic acid as compared to the disc without clavulanic acid.

\section{Results and Discussion}

A Total of 217 isolates were collected during the study period. One hundred and three (47.47\%) were Klebsiella spp. (88 K. 
pneumoniae, $15 \mathrm{~K}$. oxytoca), 90 (41.48\%) were $E$. coli and $24(11.06 \%)$ were $P$. mirabilis. Out of 217 isolates, 67 (30.88\%) were isolated from urine, $58(26.73 \%)$ from pus, $24(11.06 \%)$ from tracheal aspirates, 20 $(9.22 \%)$ from blood and $48(22.12 \%)$ were isolated from miscellaneous samples. One hundred and fifty nine $(73.27 \%)$ isolates were from males while $58(26.73 \%)$ were from females. Location- wise, $81(37.33 \%)$ patients were from ICU while $136(62.67 \%)$ were from other wards.

Out of 217 isolates, $173(79.72 \%)$ were positive for cefoxitin screen i.e., resistant to $30 \mu \mathrm{g}$ cefoxitin with diameter of zone of inhibition $\leq 18 \mathrm{~mm}$ while $44(20.28 \%)$ were negative for cefoxitin screen i.e., diameter of zone of inhibition $>18 \mathrm{~mm}$. Out of $90 \mathrm{E}$. coli isolates, $72(80.00 \%)$ were positive for cefoxitin screen while $18(20.00 \%)$ were negative. Out of $88 \mathrm{~K}$. pneumoniae isolates, $69(78.41 \%)$ were positive for cefoxitin screen while 19 (21.59\%) were negative. All $K$. oxytoca isolates were positive for cefoxitin screen. Out of $24 P$. mirabilis isolates, 17 $(70.83 \%)$ were positive for cefoxitin screen while $7(29.17 \%)$ were negative. A total of $136(62.67 \%)$ isolates were found to be AmpC $\beta$-Lactamase producers by disc potentiation test with difference in the diameters of zones of inhibition $\geq 5 \mathrm{~mm}$ considered to be positive. Out of $90 \mathrm{E}$. coli isolates, $59(65.56 \%)$ were AmpC producers while $31(34.44 \%)$ were non-AmpC producers.

Out of $88 \mathrm{~K}$. pneumoniae isolates, 51 $(57.96 \%)$ were AmpC producers while $37(42.04 \%)$ were non-AmpC producers. Out of $15 \mathrm{~K}$. oxytoca isolates, $14(93.33 \%)$ were AmpC producers while $1(6.67 \%)$ was nonAmpC producers. Out of $24 P$. mirabilis isolates, $12(50.00 \%)$ were AmpC producers while $12(50.00 \%)$ were non-AmpC producers.
There were 159/217 (73.27\%) isolates resistant for ceftazidime which included 62 $(68.89 \%)$ E. coli $(\mathrm{n}=90), \quad 80 \quad(77.67 \%)$ Klebsiella spp. (103) and $17(70.83 \%) P$. mirabilis (24). 82/159 (51.57\%) ceftazidime resistant isolates were found to be ESBL producers by double disc diffusion test using clavulanic acid as inhibitor. The total ESBL production according to double disc diffusion test was found to be 92/217 (42.40\%) of which $45(20.74 \%)$ were pure ESBL producers while $47(21.66 \%)$ were ESBL+ AmpC co-producers.

The susceptibility pattern of the AmpC and ESBL producers against other antibiotics tested and the comparison between the two groups was as mentioned in the tables 1, 2 and 3.

By definition, the AmpC $\beta$-lactamase producers are resistant to oxyiminocephalosporins and cephamycins and also not inhibited by $\beta$-lactamase inhibitors in the form of clavulanic acid and tazobactam but inhibited by chemicals like boronic acid and cloxacillin. Extended spectrum $\beta$-lactamase (ESBL) on the other hand confer resistance against fourth generation cephalosporins (cefepime, cefpirome) in addition to oxyimino-cephalosporins and are inhibited by clavulanic acid. Despite this fact, coproduction of AmpC and ESBLs has been documented in many studies (Grover et al., 2013; Doi and Paterson, 2007; Bakthavatchalu et al., 2013; Mohanty et al., 2010). Prevalence of AmpC producers have been reported to be from $8 \%$ to as high as $41.3 \%$ in various studies from India and from $1.15 \%$ to as high as $46.7 \%$ in various studies from other countries (Peter-Getzlaff et al., 2011; Grover et al., 2013; Bakthavatchalu et al., 2013; Polsfuss et al., 2011; Li et al., 2003; Singhal et al., 2005; Manoharan et al., 2012; Maraskolhr et al., 2014; Rudresh and Nagarathnamma, 2011; Tan et al., 2009; 
Helmy and Wasfi, 2014; Ingram et al., 2011; Yilmaz et al., 2013; Coudron, 2005).

In the present study found that $62.67 \%$ isolates to be AmpC $\beta$-Lactamase producers by disc potentiation test which included $E$. coli $65.56 \%, K$. pneumoniae $57.96 \%, K$. oxytoca $93.33 \%$ and P. mirabilis $50.00 \%$. Yilmaz et al., reported $39.56 \%$ isolates to be positive by disc potentiation test including $48.69 \%$ and $18.29 \% \quad E$. coli and $K$. pneumoniae respectively (Yilmaz et al., 2013). Manoharan et al reported $12.5 \%$ isolates to be AmpC producers by disc potentiation test (Manoharan et al., 2012). Maraskolhe et al., reported $35.76 \%$ isolates to be positive by disc potentiation test which included $30 \%, 85.71 \%$ and $55.56 \%$ AmpC producers amongst $E$. coli, $K$. pneumoniae and $K$. oxytoca respectively (Maraskolhe et al., 2014). In a study by Rudresh, $41.25 \%$ isolates were positive by disc potentiation test which included $41.30 \%$ positive isolates of $E$. coli, $45.45 \%$ Klebsiella spp. and $25 \%$ positive isolates of $P$. mirabilis (Rudresh and Nagarathnamma, 2011). Bakthavatchalu et al., reported $25.87 \%$ isolates positive by disc potentiation test including $18.26 \%, 42.37 \%$ and $24.14 \%$ isolates amongst $E$. coli, $K$. pneumoniae and $P$. mirabilis respectively (Bakthavatchalu et al., 2013). We found higher number of AmpC producers by disc potentiation test as compared to the other studies.

In our study, we found $41.48 \%$ isolates to be pure AmpC producers, $21.20 \%$ to be pure ESBL producers and $21.20 \%$ were AmpC+ ESBL co-producers. Shoorashetty et al., reported $6 \%$ and $41 \%$ isolates to be pure $\mathrm{AmpC}$ and pure ESBL producers respectively while $27.5 \%$ isolates to be AmpC and ESBL co-producers (Shoorashetty et al., 2011). Bakthavatchalu et al., reported $5.4 \%$ and $26.25 \%$ pure AmpC and pure ESBL producers respectively with $20.46 \%$ AmpC and ESBL co-producers (Bakthavatchalu et al., 2013). Mohanty et al., reported 20.35\% and $3.54 \%$ pure AmpC and pure ESBL producers respectively with $58.41 \%$ isolates to be AmpC ESBL co-producers (Mohanty et al., 2010). Grover et al reported 4.96 and $30.15 \%$ isolates to be pure AmpC and pure ESBL producers respectively with $9.92 \%$ isolates to be AmpC ESBL co-producers (Grover et al., 2013).

There was significant difference between the pure AmpC producing, pure ESBL producing, AmpC ESBL co-producing and AmpC ESBL non-producing isolates of E. coli, Klebsiella spp. and $P$. mirabilis regarding the resistance pattern against amoxycillin-clavulanate, piperacillin-tazobactam and co-trimoxazole for which the higher number of pure AmpC producers or AmpC ESBL co-producers were found to be resistant as compared to pure ESBL producers.

In addition, there was significant difference in the resistance pattern against imipenem and chloramphenicol among pure AmpC producing, pure ESBL producing, AmpC ESBL co-producing and AmpC ESBL nonproducing isolates of $E$. coli, sulfonamide in case of Klebsiella spp and imipenem in case of $P$. mirabilis isolates. The difference can be justified by the fact that the AmpC producers are not inhibited by the beta lactamase inhibitors like clavulanic acid.

Yilmaz et al., reported significant resistance against ceftazidime, cefotaxime and amoxycillin+ clavulanic acid in case of AmpC producers, (Yilmaz et al., 2013). Grover et al., reported a significant resistance against gentamicin, third generation cephalosporins, cefepime and fluoroquinolones by $\beta$-lactamase producers (Grover et al., 2013). 
Table.1 Antimicrobial susceptibility of E. coli isolates

\begin{tabular}{|c|c|c|c|c|c|}
\hline \multirow[t]{2}{*}{ Antimicrobial } & \multicolumn{4}{|c|}{ E. coli $(90)$} & \multirow[t]{2}{*}{$p$ Value } \\
\hline & $\begin{array}{c}\text { Pure AmpC } \\
\text { Producer (34) }\end{array}$ & $\begin{array}{c}\text { Pure ESBL } \\
\text { Producer (17) }\end{array}$ & $\begin{array}{c}\text { AmpC ESBL Co- } \\
\text { producer (25) }\end{array}$ & $\begin{array}{l}\text { Non-AmpC Non- } \\
\text { ESBL (14) }\end{array}$ & \\
\hline Ampicillin & $23(67.65 \%)$ & $10(58.82 \%)$ & $20(\%)$ & $6(42.86 \%)$ & 0.1160 \\
\hline Ceftazidime & $25(73.53 \%)$ & $*$ & $*$ & $1(7.14 \%)$ & NA \\
\hline $\begin{array}{l}\text { Ceftazidime+ } \\
\text { Clavulanate }\end{array}$ & $34(100 \%)$ & $*$ & $*$ & $1(7.14 \%)$ & NA \\
\hline Ceftriaxone & $19(55.88 \%)$ & $*$ & $*$ & $4(28.57 \%)$ & NA \\
\hline Cefepime & $9(26.47 \%)$ & $*$ & $*$ & $2(14.29 \%)$ & NA \\
\hline Aminoglycosides & $18(52.94 \%)$ & $6(35.29 \%)$ & $17(68 \%)$ & $8(57.14 \%)$ & 0.2179 \\
\hline $\begin{array}{l}\text { Amoxycillin+ } \\
\text { Clavulanate }\end{array}$ & $32(94.12 \%)$ & $6(35.29 \%)$ & $1(4 \%)$ & $6(42.86 \%)$ & $<0.0001$ \\
\hline $\begin{array}{l}\text { Piperacillin+ } \\
\text { Tazobactam }\end{array}$ & $19(55.88 \%)$ & $6(35.29 \%)$ & $24(96 \%)$ & $5(35.71 \%)$ & 0.0001 \\
\hline Quinolones & $21(61.76 \%)$ & $7(41.18 \%)$ & $13(52 \%)$ & $5(35.71 \%)$ & 0.3141 \\
\hline Imipenem & $17(50 \%)$ & $4(23.53 \%)$ & $15(60 \%)$ & $4(28.57 \%)$ & 0.0625 \\
\hline Co-trimoxazole & $23(67.65 \%)$ & $7(41.18 \%)$ & $20(80 \%)$ & $6(42.86 \%)$ & 0.0265 \\
\hline Sulfonamides & $19(55.88 \%)$ & $6(35.29 \%)$ & $14(56 \%)$ & $7(50 \%)$ & 0.5206 \\
\hline Aztreonam & $24(70.59 \%)$ & $*$ & $*$ & $4(28.57 \%)$ & NA \\
\hline Tetracycline & $18(52.94 \%)$ & $9(52.94 \%)$ & $15(60 \%)$ & $7(50 \%)$ & 0.9256 \\
\hline Chloramphenicol & $20(58.82 \%)$ & $6(35.29 \%)$ & $10(40 \%)$ & $1(7.14 \%)$ & 0.0101 \\
\hline Nitrofurantoin & $3 / 11(27.27 \%)$ & $6 / 10(60 \%)$ & $7 / 11(63.64 \%)$ & $1 / 8(12.5 \%)$ & 0.0642 \\
\hline
\end{tabular}

*ESBL producing isolates are resistant to other cephalosporins, and aztreonam 
Table.2 Antimicrobial susceptibility of Klebsiella Spp. Isolates

\begin{tabular}{|c|c|c|c|c|c|}
\hline \multirow[t]{2}{*}{ Antimicrobial } & \multicolumn{4}{|c|}{ Klebsiella spp. (103) } & \multirow[t]{2}{*}{$p$ Value } \\
\hline & $\begin{array}{c}\text { Pure AmpC } \\
\text { Producer }(48)\end{array}$ & $\begin{array}{c}\text { Pure ESBL } \\
\text { Producer (22) }\end{array}$ & $\begin{array}{c}\text { AmpC ESBL Co- } \\
\text { producer (17) }\end{array}$ & $\begin{array}{c}\text { Non-AmpC } \\
\text { Non-ESBL(16) }\end{array}$ & \\
\hline Ampicillin & $* *$ & $* *$ & $* *$ & $* *$ & NA \\
\hline Ceftazidime & $39(81.25 \%)$ & $*$ & $*$ & $5(31.25 \%)$ & NA \\
\hline $\begin{array}{l}\text { Ceftazidime+ } \\
\text { Clavulanate }\end{array}$ & $48(100 \%)$ & $*$ & $*$ & $5(31.25 \%)$ & NA \\
\hline Ceftriaxone & $28(58.33 \%)$ & $*$ & $*$ & $4(25 \%)$ & NA \\
\hline Cefepime & $15(31.25 \%)$ & $*$ & $*$ & $3(18.75 \%)$ & NA \\
\hline Aminoglycosides & $30(62.5 \%)$ & $8(36.36 \%)$ & $11(64.71 \%)$ & $8(50 \%)$ & 0.1726 \\
\hline $\begin{array}{l}\text { Amoxycillin+ } \\
\text { Clavulanate }\end{array}$ & $46(95.83 \%)$ & $11(50 \%)$ & $3(17.65 \%)$ & $8(50 \%)$ & $<0.0001$ \\
\hline $\begin{array}{l}\text { Piperacillin+ } \\
\text { Tazobactam }\end{array}$ & $25(52.08 \%)$ & $9(40.91 \%)$ & $15(88.24 \%)$ & $6(37.5 \%)$ & 0.0101 \\
\hline Quinolones & $26(54.17 \%)$ & $6(27.27 \%)$ & $11(64.71 \%)$ & $6(37.5 \%)$ & 0.0681 \\
\hline Imipenem & $26(54.17 \%)$ & $9(40.91 \%)$ & $12(70.59 \%)$ & $8(50 \%)$ & 0.3229 \\
\hline Co-trimoxazole & $28(58.33 \%)$ & $7(31.82 \%)$ & $9(52.94 \%)$ & $9(56.25 \%)$ & 0.2152 \\
\hline Sulfonamides & $32(66.67 \%)$ & $11(50 \%)$ & $11(64.71 \%)$ & $4(25 \%)$ & 0.0254 \\
\hline Aztreonam & $28(58.33 \%)$ & $*$ & $*$ & $9(56.25 \%)$ & NA \\
\hline Tetracycline & $29(60.42 \%)$ & $9(40.91 \%)$ & $7(41.18 \%)$ & $7(43.75 \%)$ & 0.3105 \\
\hline Chloramphenicol & $23(47.92 \%)$ & $6(27.27 \%)$ & $8(47.06 \%)$ & $5(31.25 \%)$ & 0.3139 \\
\hline Nitrofurantoin & $5 / 8(62.5 \%)$ & $1 / 8(12.5 \%)$ & $2 / 5(40 \%)$ & $2 / 3(66.67 \%)$ & 0.1714 \\
\hline
\end{tabular}

*ESBL producing isolates are resistant to other cephalosporins, and aztreonam **Intrinsic resistance 
Table.3 Antimicrobial susceptibility of $P$. mirabilis isolates

\begin{tabular}{|c|c|c|c|c|c|}
\hline \multirow[t]{2}{*}{ Antimicrobial } & \multicolumn{4}{|c|}{ P. mirabilis (24) } & \multirow[t]{2}{*}{$p$ Value } \\
\hline & $\begin{array}{l}\text { Pure AmpC } \\
\text { Producer }(8)\end{array}$ & $\begin{array}{c}\text { Pure ESBL } \\
\text { Producer (7) }\end{array}$ & $\begin{array}{c}\text { AmpC ESBL Co- } \\
\text { producer (4) }\end{array}$ & $\begin{array}{c}\text { Non-AmpC } \\
\text { Non-ESBL }(5)\end{array}$ & \\
\hline Ampicillin & $3(37.5 \%)$ & $1(14.29 \%)$ & $4(100 \%)$ & $2(40 \%)$ & 0.0498 \\
\hline Ceftazidime & $5(62.5 \%)$ & $*$ & $*$ & $2(40 \%)$ & NA \\
\hline $\begin{array}{l}\text { Ceftazidime+ } \\
\text { Clavulanate }\end{array}$ & $7(87.5 \%)$ & $*$ & $*$ & $2(40 \%)$ & NA \\
\hline Ceftriaxone & $4(50 \%)$ & $*$ & $*$ & $4(80 \%)$ & NA \\
\hline Cefepime & $2(25 \%)$ & $*$ & $*$ & $2(40 \%)$ & NA \\
\hline Aminoglycosides & $3(37.5 \%)$ & $1(14.29 \%)$ & $3(75 \%)$ & $3(60 \%)$ & 0.1922 \\
\hline $\begin{array}{l}\text { Amoxycillin+ } \\
\text { Clavulanate }\end{array}$ & $7(87.5 \%)$ & $1(14.29 \%)$ & 0 & $2(40 \%)$ & 0.0076 \\
\hline $\begin{array}{l}\text { Piperacillin+ } \\
\text { Tazobactam }\end{array}$ & $3(37.5 \%)$ & $1(14.29 \%)$ & $4(100 \%)$ & $1(20 \%)$ & 0.0302 \\
\hline Quinolones & $5(62.5 \%)$ & $3(42.86 \%)$ & $3(75 \%)$ & $2(40 \%)$ & 0.6396 \\
\hline Imipenem & $5(62.5 \%)$ & 0 & $3(75 \%)$ & $2(40 \%)$ & 0.0401 \\
\hline Co-trimoxazole & $7(87.5 \%)$ & $2(28.57 \%)$ & $4(100 \%)$ & $2(40 \%)$ & 0.0286 \\
\hline Sulfonamides & $4(50 \%)$ & $5(71.43 \%)$ & $2(50 \%)$ & $3(60 \%)$ & 0.8393 \\
\hline Aztreonam & $5(62.5 \%)$ & $*$ & $*$ & $4(80 \%)$ & NA \\
\hline Tetracycline & $* * *$ & $* * *$ & $* * *$ & $* * *$ & NA \\
\hline Chloramphenicol & $3(37.5 \%)$ & $1(14.29 \%)$ & $2(50 \%)$ & $1(20 \%)$ & 0.5595 \\
\hline Nitrofurantoin & $* * *$ & $* * *$ & $* * *$ & $* * *$ & NA \\
\hline
\end{tabular}

*ESBL producing isolates are resistant to other cephalosporins, and aztreonam $* * *$ Intrinsic resistance 
Image 1 Disc Potentiation Test [CX: Cefoxitin; CX+BA: Cefoxitin plus boronic acid]. Difference in the diameters of zones of inhibition $>5 \mathrm{~mm}$ indicates positive test

(AmpC $\beta$ - lactamase producer)

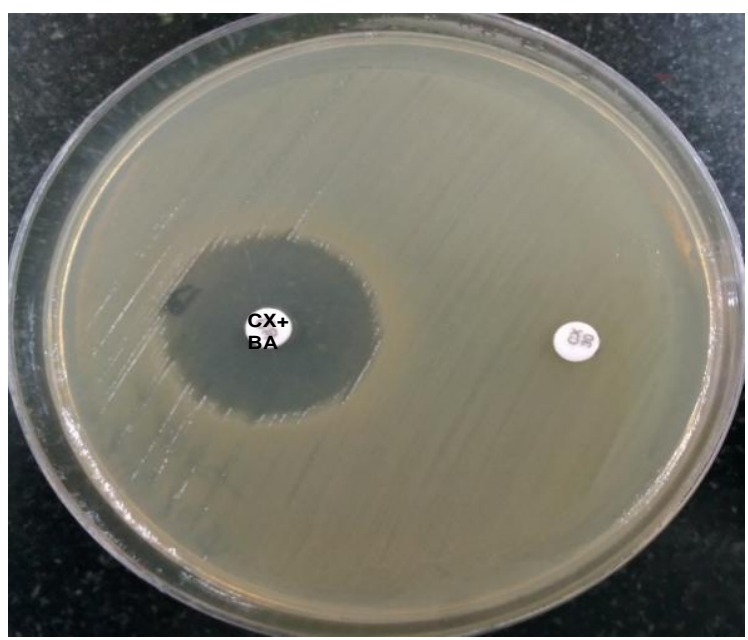

Image 2 Double Disc Diffusion Test [CAZ: Ceftazidime; CAC: Ceftazidime plus clavulanic acid]. Difference in the diameters of zones of inhibition $>5 \mathrm{~mm}$ indicates positive test (Extended Spectrum $\beta$ - lactamase producer)

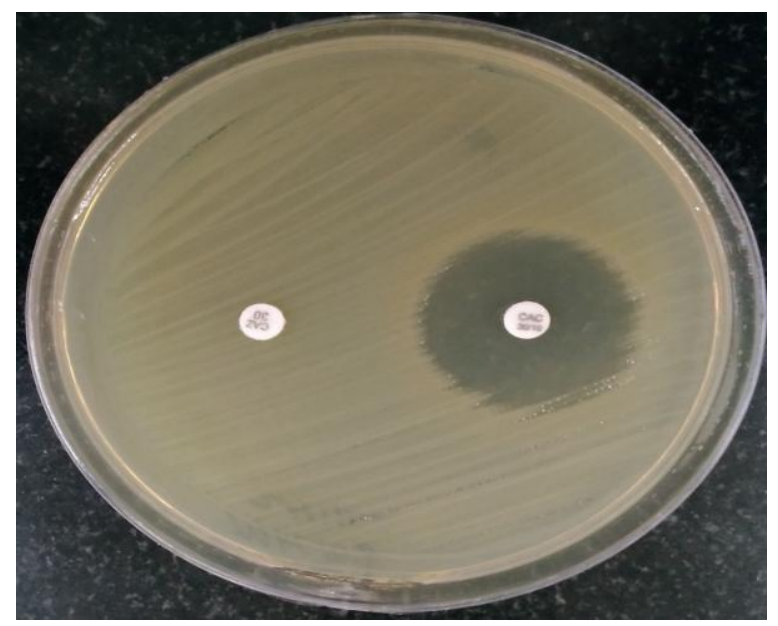

Bakthavatchalu et al., reported $97 \%,>80 \%$, $63 \%, \approx 70 \%$, and $>50 \%$ resistance against ampicillin, third generation cephalosporins, cefepime, aminoglycosides and fluoroquinolones respectively (Bakthavatchalu et al., 2013). Vandana et al., reported 67\%,92\%, 90\%, 82\%, 48\%, and 97\% resistance against amikacin, cefepime, co-trimoxazole, gentamicin, piperacillin+ tazobactam and aztreonam respectively (Vandana and Hannavar, 2009).
The above quoted studies reported imipenem resistance to be nil as against in our study we found $54.24 \%, 58.46 \%$ and $66.67 \%$ resistance against imipenem amongst AmpC producing E. coli, Klebsiella spp. and P. mirabilis isolates respectively while $45.24 \%$ and $53.85 \%$ resistance against imipenem amongst ESBL producing E. coli and Klebsiella spp. isolates respectively. The higher resistance against cefepime in the studies by Vandana $e t$ al., and Bakthavatchalu et al., as compared to 
our study may be because the former has studied the AmpC production among ESBL producers and the later has quoted the resistance pattern of AmpC and ESBL producers together and the ESBL producers by definition are resistant to fourth generation cephalosporins (cefepime).

The higher resistance against imipenem in AmpC and ESBL producing isolates could be because of the beta lactamase producing isolates producing carbapenemase or the additional mechanism in the form of efflux.

\section{References}

Bakthavatchalu, S., Shakthivel, U., Mishra, T. 2013. Detection of ESBL among Ampc producing Enterobacteriaceae using inhibitor-based method. Pan Afr. Med. J., 14: 28.

CLSI. 2012. Performance Standards for Antimicrobial Susceptibility Testing. Approved Standards; twenty-third Informational Supplement. M100-S22 Wayne, PA: Clinical and Laboratory Standards Institute.

Coudron, P.E. 2005. Inhibitor-Based Methods for Detection of Plasmid-Mediated AmpC $\beta$-Lactamases in Klebsiella spp., Escherichia coli, and Proteus mirabilis. J. Clin. Microbiol., 43(8): 4163-7.

Crichton, P.B. 1996. Enterobacteriaceae: Escherichia, Klebsiella, Proteus and other genera. In: Collee JG, Marmion $\mathrm{BP}$, Fraser AG et al, editors. Mackie and McCartney Practical Medical Microbiology. $14^{\text {th }}$ ed. Haryana, India: Churchill Livingstone.

Doi, Y., Paterson, D.L. 2007. Detection of plasmid-mediated class C $\beta$-lactamases. Int. J. Infect. Dis., 11: 191-7

Donnenberg, M.S. 2012. Enterobacteriaceae. In: Mendell GL, Bennett JE, Dolin R. Principles and Practice of Infectious
Diseases. $7^{\text {th }}$ ed. United States. Churchill Livingstone.

Grover, N., Sahni, A.K., Bhattacharya, S. 2013. Therapeutic challenges of ESBLS and AmpC beta-lactamase producers in a tertiary care center. Med. J. Armed Forces India, 69: 4-10.

Helmy, M.M. and Wasfi, R. 2014. Phenotypic and Molecular Characterization of Plasmid Mediated AmpC $\beta$-Lactamases among Escherichia coli, Klebsiella spp., and Proteus mirabilis Isolated from Urinary Tract Infections in Egyptian Hospitals. BioMed. Res. Int., 1-9.

Ingram, P.R., Inglis, T.J.J., Vanzetti, T.R., Henderson, B.A., Harnett, G.B. and Murray, R.J. 2011. Comparison of methods for AmpC $\beta$-lactamase detection in Enterobacteriaceae. J. Med. Microbiol., 60: 715-21.

Johanson, W.G., Pierce, A.K. and Sanford, J.P. 1969. Changing pharyngeal bacterial flora of hospitalized patients: emergence of gram-negative bacilli. $N$ Engl. J. Med., 281: 1137-40.

Li, Y., Li, Q. and Du, Y. 2008. Prevalence of Plasmid-Mediated AmpC $\beta$-Lactamases in a Chinese University Hospital from 2003 to 2005: First Report of CMY-2Type AmpC $\beta$-Lactamase Resistance in China. J. Clin. Microbiol., 46(4): 131721.

Mackowiak, P.A., Martin, R.M., Jones, S.R. and Smith, J.W. 1978. Pharyngeal colonization by gram-negative bacilli in aspiration-prone persons. Arch. Intern Med., 138: 1224-7.

Manoharan, A., Sugumar, M. and Kumar, A. 2012. Phenotypic \& molecular characterization of AmpC $\beta$-lactamases among Escherichia coli, Klebsiella spp. \& Enterobacter spp. from five Indian Medical Centers. Indian J. Med. Res., 135: 359-64.

Maraskolhe, D.L., Deotale, V.S., Mendiratta, D.K. and Narang, P. 2014. Comparison 
of three Laboratory Tests for Detection of Ampc $\beta$ Lactamases in Klebsiella Species and E. Coli. J. Clin. Diagn. Res., 8(6): 5-8

Mohanty, S., Gaind, R. and Ranjan, R. 2010. Use of the cefepime-clavulanate ESBL Etest for detection of extended-spectrum beta-lactamases in AmpC co-producing bacteria. J. Infect. Dev. Ctries., 4(1): 249.

Peter-Getzlaff, S., Polsfuss, S., Poledica, M., Hombach, M., Giger, J., Böttger, G.C., Zbinden, R. and Bloemberg, G.V. 2011. Detection of AmpC Beta-Lactamase in Escherichia coli: Comparison of Three Phenotypic Confirmation Assays and Genetic Analysis. J. Clin. Microbiol., 49(8): 2924-32.

Pitout, J.D., Le, P.G., Moore, K.L., Church, D.L. and Gregson, D.B. Detection of AmpC $\beta$-lactamases in Escherichia coli, Klebsiella spp., Salmonella spp. and Proteus mirabilis in a regional clinical microbiology laboratory. Clin. Microbiol. Infect., 16: 165-170.

Polsfuss, S., Bloemberg, G.V., Giger, J., Meyer, V., Böttger, G.C. and Hombach, M. 2011. Practical Approach for Reliable Detection of AmpC BetaLactamase Producing Enterobacteriaceae. J. Clin. Microbiol., 49(8): 2798-803.

Rudresh, S.M. and Nagarathnamma, T. 2011. Two simple modifications of modified three-dimensional extract test for detection of AmpC $\beta$-lactamases among the members of family Enterobacteriaceae. Chron Young Sci., 2: 42-6.
Savard, P. and Perl, T.M. 2012. A call for action: managing the emergence of multidrug-resistant Enterobacteriaceae in the acute care settings. Curr. Opin. Infect. Dis., 25: 371-7.

Shoorashetty, R.M., Nagarathnamma, T. and Pratibha, J. 2011. Comparison of boronic acid disk potentiation test and cefepime-clavulanic acid method for the detection of ESBL among AmpCproducing Enterobacteriaceae. Indian J. Med. Microbiol., 29: 297-301.

Singhal, S., Mathur, T., Khan, S., Upadhyay, D.J., Chugh, S., Gaind, R. and Rattan, A. 2005. Evaluation of Methods for AmpC $\beta$ Lactamase in Gram Negative Clinical Isolates from Tertiary Care Hospitals. Indian J. Med. Microbiol., 23(2): 120-4.

Tan, T.Y., Yong, N.g. L.S. and He, J. 2009. Evaluation of Screening Methods To Detect Plasmid-Mediated AmpC in Escherichia coli, Klebsiella pneumoniae, and Proteus mirabilis. Antimicrob. Agents Chemother., 53(1): 146-9.

Vandana, K.E. and Honnavar, P. 2009. AmpC Beta Lactamases Among ESBL Producing Escherichia coli and Klebsiella pneumoniae- If You Don't Look, You Won't Find. J. Clin. Diagn. Res., 3: 1653-6.

Yilmaz, N.O., Agus, N., Bozcal, E., Oner, O. and Uzel, A. 2013. Detection of plasmid-mediated AmpC $\beta$-lactamase in Escherichia coli and Klebsiella pneumoniae. Indian J. Med. Microbiol., 31(1): 53-9.

\section{How to cite this article:}

Dudhat, V.L., C.N. Chaudhari, Mahadevan Kumar, N. Grover and Das, N.K. 2017. AmpC and Extended Spectrum Beta Lactamase Producing Isolates of E. coli, Klebsiella spp. and $P$. mirabilis in a Tertiary Care Center and their Sensitivity to Other Antibiotics. Int.J.Curr.Microbiol.App.Sci. 6(3): 868-877. doi: https://doi.org/10.20546/ijcmas.2017.603.102 